Article

\title{
Experimental Study on Flat-Glass Heating and Edge-Sealing Using Multiple Microwave Sources
}

\author{
Jae Kyung Kim ${ }^{1}$, Young Shin Kim ${ }^{1}$ and Euy Sik Jeon ${ }^{1,2, *}$ \\ 1 Industrial Technology Research Institute, Kongju National University, Cheonan-daero, Seobuk-gu, \\ Cheonan-si 31080, Chungcheongnam-do, Korea; kimjk@kongju.ac.kr (J.K.K.); \\ people9318@kongju.ac.kr (Y.S.K.) \\ 2 Department of Mechanical Engineering, Graduate School, Kongju National University, Cheonan-daero, \\ Seobuk-gu, Cheonan-si 31080, Chungcheongnam-do, Korea \\ * Correspondence: osjun@kongju.ac.kr; Tel.: +82-41-521-9284
}

Received: 23 October 2019; Accepted: 13 November 2019; Published: 15 November 2019

check for updates

\begin{abstract}
There has been a recent surge of interest in vacuum insulating glass (VIG) due to its excellent thermal insulation performance. Vacuum glazing is necessary for high-performance sealing solders and various applications in sealing technology. This paper describes experimental studies into heating and edge-sealing of flat glass using microwaves. Electric-thermal coupled analysis using ANSYS was employed and heating and edge-sealing experiments were conducted on flat glass. In order to ensure a uniform electric field distribution in the microwave chamber, the electric field and temperature distributions were analyzed according to waveguide patterns. In addition, the electric field and temperature distribution were analyzed with the inclusion of carbon susceptor plates. Based on the electric simulation results by waveguide pattern, a microwave heating chamber was fabricated, and a basic experiment was conducted on both heating and edge-sealing of the glass. The cross-section of the sealed glass confirmed that it was sealed without cracks or breakage.
\end{abstract}

Keywords: vacuum glazing; flat glass; heating; edge-sealing; microwave; multiple sources

\section{Introduction}

Due to the thermal vulnerability of glass windows, various glass systems have been developed to solve problems related to condensation and energy consumption, using not only double-sheet glass and triple-plate glass but also low-emissivity coatings (low- $\varepsilon$ coating) and gas-injection technology. There is currently a great deal of interest in vacuum insulating glass (VIG) due to its excellent thermal insulation performance [1].

VIG windows typically have a structure that is evacuated and sealed between at least two glass substrates at a constant distance and low pressure. The glass plates are interconnected by a perimeter frame seal, and pillars are typically included between the glass substrates to maintain constant spacing between them. The low-pressure environment between the substrates prevents their breakage.

The edge-sealing process is a technique whereby glass frit bonding is applied to the glass surface to seal two pieces of glass together. Numerous studies on this process have been conducted [2,3]. In processes that employ frit glass, stress is formed on the bonding surface between the frit and glass, based on the difference in the thickness of the frit layer. If this stress exceeds an allowable level of stress for the glass or sealing layer, the glass, sealing layer, or sealing interface could break [4].

Sealing processes that employ lasers present the problem that the vacuum glass easily forms pores at the sealing edge during the process [5]. Using hydrogen gas torches in the edge-sealing process resolves the stress problem of the frit. However, the resulting sealed edges sag, rendering 
these inappropriate for panel fabrication [6,7]. Vacuum glazing therefore requires high-performance sealing-solder and edge-sealing technology.

In this paper, the heating and edge-sealing of glass were performed using microwave radiation. Due to its unique heating principles, microwave heating is characterized by efficient and internal heating which is environmentally friendly [8]. Multiple sources were applied to improve the heating-temperature distribution uniformity of the glass. Temperature distribution analysis was performed according to the pattern of the measured waveguides. Based on this data, a processing chamber was manufactured, and sealing experiments were performed. An experiment on the heating and temperature distribution of flat glass using microwaves was thus conducted, and the potential of this edge-sealing approach for application in vacuum glazing manufacturing processes was evaluated.

\section{Operating Principles and Microwave System Design}

\subsection{Operating Principles}

Microwave energy interacts with dielectric materials by inducing rotations in molecules or ion-pair dipoles, with a subsequent conversion to heat. The polarization principles of these processes are described by the following expressions:

$$
\begin{gathered}
\varepsilon=\varepsilon_{0} \varepsilon_{r}=\varepsilon_{o}\left(\varepsilon^{\prime}-j \varepsilon^{\prime \prime}\right)=\varepsilon_{o}\left(\varepsilon^{\prime}+j \frac{\sigma}{\omega \varepsilon_{o}}\right) \\
\varepsilon^{\prime \prime}=\frac{\sigma}{\omega \varepsilon_{o}} \\
\tan \delta=\frac{\varepsilon^{\prime \prime}}{\varepsilon^{\prime}}=\frac{\sigma}{\omega \varepsilon^{\prime} \varepsilon_{o}}
\end{gathered}
$$

where

$\varepsilon$-permittivity,

$\varepsilon_{0}$ free space dielectric constant,

$\varepsilon \prime$-real part of the complex permittivity,

$\varepsilon^{\prime \prime}$-imaginary part of the complex permittivity,

$\sigma$-conductivity $(1 / \Omega)$,

$\omega$-angular frequency $(\mathrm{rad} / \mathrm{s})$,

$\tan \delta$-dielectric loss tangent $(\tan \delta<0.01$, dielectric).

Equations (1)-(3) show the loss tangent $(\tan \delta)$ equation indicating the extent of loss. When the conductivity $(\sigma(1 / \Omega))$ increases, the permittivity $(\varepsilon(F / m))$ of the vacuum also increases.

The extent of the loss tangent value becomes large when the values of the real $(\varepsilon /(F / m))$ and imaginary $\left(\varepsilon^{\prime \prime}(F / m)\right)$ parts of the relative dielectric constant, the value of the frequency $\left(f=\frac{1}{2 \pi} \omega(\mathrm{Hz})\right)$ becomes small; and in the case of the dielectric, when the loss is $\leq 0.01$.

The loss tangent value is influenced by the microwave power conversion per unit volume $\left(P_{c}\right)$ that is due to the electric field incidence on the medium. This can be expressed by the heat conversion ratio in Equation (4).

$$
P_{c}=\sigma^{2}\left|E_{i}\right|^{2}=\omega \varepsilon_{0} \varepsilon \prime(\tan \delta)\left|E_{i}\right|^{2}\left(W / m^{3}\right)
$$

where $E_{i}$-internal electric field intensity at microwave frequency $(\mathrm{V} / \mathrm{m})$,

$P_{c}$ 一the microwave power conversion per unit volume $\left(\mathrm{W} / \mathrm{m}^{3}\right)$.

The microwave power conversion per unit volume $\left(P_{c}\right)$ is proportional to both the square of the internal electric field intensity at microwave frequencies $\left(E_{i}\right)$ and the conductivity $(\sigma)$. The microwave power conversion per unit volume will be affected by frequency and loss tangent value when the 
internal electric field intensity at microwave frequency is the constant. Thus, the microwave power conversion per unit volume affects the temperature deviation $(\Delta \mathrm{T})$, as described by Equation (5) [9].

$$
\Delta \mathrm{T}=\frac{P_{c} \Delta t}{\rho C_{p}}=\frac{2 \pi f \varepsilon_{0} \varepsilon^{\prime \prime}\left|E_{i}\right|^{2} \Delta t}{\rho C_{p}}\left({ }^{\circ} \mathrm{C}\right)
$$

where

$\Delta \mathrm{T}$-increased temperature $\left({ }^{\circ} \mathrm{C}\right)$,

$\Delta \mathrm{t}$-temperature rise time (s),

$\rho$ - the density of the material to be heated $\left(\mathrm{kg} / \mathrm{m}^{3}\right)$,

$C_{p}$-specific heat of the material to be heated $\left(\mathrm{J} / \mathrm{kg} \cdot{ }^{\circ} \mathrm{C}\right)$.

$\Delta \mathrm{t}$ indicates the heating time, the specific heat $\left(\mathrm{J} / \mathrm{kg} \cdot{ }^{\circ} \mathrm{C}\right)$ of the dry substance, and the density $\left(\mathrm{kg} / \mathrm{m}^{3}\right)$ of the dry substance. This temperature deviation is proportional to the microwave irradiation time when microwave power conversion per unit volume is fixed. Furthermore, the temperature deviation decreases when the specific heat of the dry substance is high or the density is increased, and when irradiation time is increased.

\subsection{Microwave System Design}

In order to prevent radiation of electromagnetic waves, the microwaves must be confined inside a heating chamber. Microwave signal is guided from the source (Magnetron) to the cavity using waveguides. Waves guided by waveguide create or excite the resonant mode or non-uniform electric field within the heating chamber. Uneven electric field distribution in the heating chamber results in non-uniform microwave heating, which degrades the drying and heating performance and causes magnetron damage. Many studies have been conducted in an effort to alleviate the problem of non-uniform energy distribution [10].

Methods for improving microwave heating uniformity can be roughly divided into two types: shaping electric field distribution of microwaves and uniformity of microwave energy absorption in substances.

Methods for improving temperature uniformity in the microwave chamber include using the mode-stirrer configuration [11], various microwave sources with different frequencies [12], microwave cavity rotation tables [13], microstrip microwave transducers [14], and multiple microwave sources [15]. The method that involves using multiple microwave sources is the most common among these approaches. The multiple sources largely depend on the arrangement and size of the object to be heated, moisture distribution, and amount of moisture [16,17].

In the sealing process employed in this study, in order to reach the glass transition temperature, after heating to a temperature of at least $560{ }^{\circ} \mathrm{C}$, a step of pressing and sealing the edges of the glass is applied. It is therefore impossible to apply advanced methods such as power control and a turntable, or reflectors. In this study, we simulate the electric field distribution according to the multiple waveguides $(6 \mathrm{~kW})$ and the waveguide pattern, to derive an appropriate pattern in which the electric field distribution is uniform. In order to prevent fractures from occurring in the concentrated section of the microwaves, we improved temperature uniformity by applying a thermal diffuser object that performs the absorption function.

The operating frequency of a single waveguide is determined by the width $\times$ length of the standard. The WR-340 waveguide size, with dimensions of $86.36 \mathrm{~mm} \times 43.18 \mathrm{~mm}$, is suitable for the $2.45 \mathrm{GHz}$ frequency band used for glass sealing using microwaves. As a frequency band of $2.17-2.45 \mathrm{GHz}$ is used, WR-340 was applied. The microwave chamber for heating and sealing the edges of the glass panes has a shield structure of dimensions $400 \mathrm{~mm} \times 400 \mathrm{~mm} \times 184 \mathrm{~mm}$.

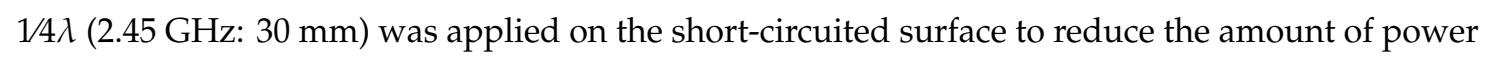
reflected at the excitation part of the waveguide. Figure 1 shows the cross-section of microwave chamber and internal structure used for glass heating. 


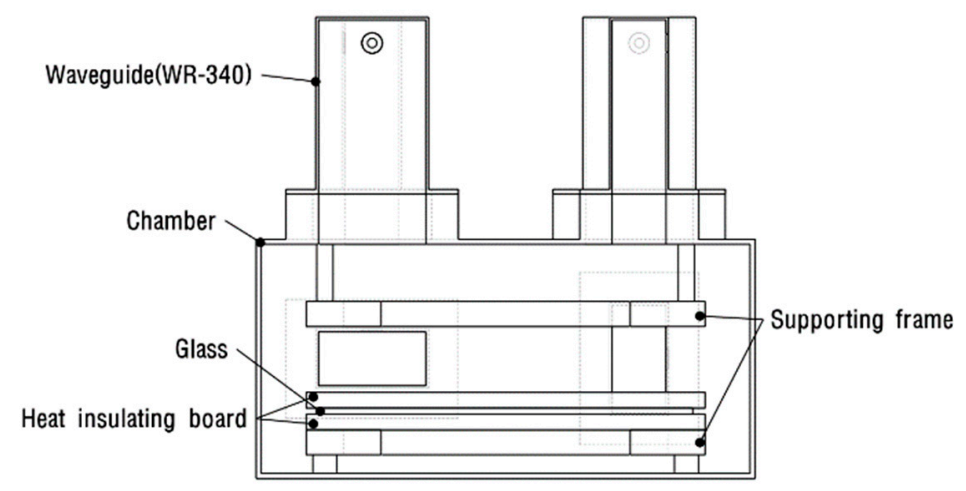

Figure 1. A schematic illustration of the $6 \mathrm{~kW}$ microwave chamber model used in the current study.

\section{Numerical Analysis of Temperature Distribution in the Furnace Chamber}

Simulations were conducted through coupled HFSS-Icepak analysis of ANSYS software for electric field and temperature distribution analysis in the chamber. Not all glasses are necessarily good microwave absorbers; and for this reason, in most cases these cannot be easily heated [18].

In the case of the soda-lime glass used in this study, the value of the loss tangent can be made at the boundary of the dielectric which varies from 0.01 to 0.05 . In addition, heat by microwave power conversion per unit volume was not diffused widely because of the thermal conductivity of the glass being between 1.1 and $1.4 \mathrm{~W} / \mathrm{mK}$; concentrated heating is performed at a specific part of the glass and there is heat loss due to convection. As a result, it is possible to analyze the distribution of the electric field; however, it is impossible to accurately analyze the temperature distribution. Therefore, a method that can be applied in this chamber to confirm the electric field distribution is by changing the vertical distance from the glass at which it is heated and the array pattern of the waveguide. However, according to a previous study, temperature distribution can be altered changing the vertical distance according to the height of the generation point, such as the cold and hot points, but this did not result in any significant improvement in the uniformity [19]. Therefore, in this simulation, the waveguide array was approximately classified into four types, and the electric field distribution was simulated in the chamber according to these patterns. Microwave multiple sources use six $1 \mathrm{~kW}$ magnetrons. Each magnetron and waveguide must be placed with a $90^{\circ}$ angle between the waveguides to eliminate interference between wavelengths. Four types of waveguide array were constructed with a general pattern that can have an angle of $90^{\circ}$.

It is difficult to accurately analyze the temperature distribution because of heating due to the dielectric properties of glass [20]. An appropriate pattern of A was therefore derived through relative comparisons between the electric field distribution and the temperature distribution as seen in Figure 2. In these analyses, it was confirmed that absorption increases at the side and edge parts of the glass due to the microwave characteristics, showing that temperature changes occur preferentially from the sides and edges [21]. Although temperature deviation decreases when the arrangement of the waveguide is symmetric, a phenomenon in which high temperature is concentrated in specific areas appears. In the case of the arrangement of pattern A (Figure 2a), the maximum voltage of the electric field distribution appears at a level half that of the other patterns, and the difference between the maximum and minimum temperatures was also minimal at $20 \%$ when compared to other patterns. This suggests that the temperature distribution of pattern $\mathrm{A}$ is more uniform than those of the other patterns. This result indicates that when the waveguide arrangement structure is symmetric, each waveguide can have a vertical structure, and the electric field distribution becomes uniform. Figure 2 shows the four waveguide patterns, and Figure 3 shows the simulation results for each pattern. The waveguide patterns are arranged symmetrically, and the irradiation location of the microwave is maintained while rotating the system with reference to the symmetrical center. 


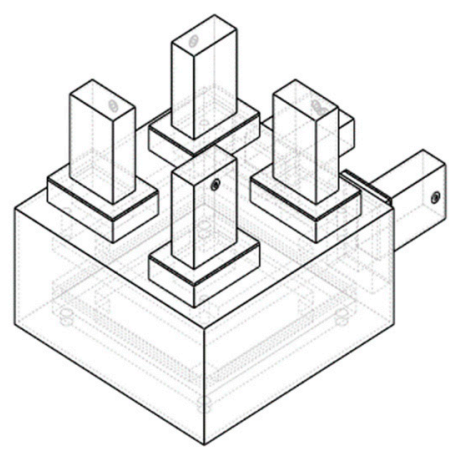

(a) Pattern A

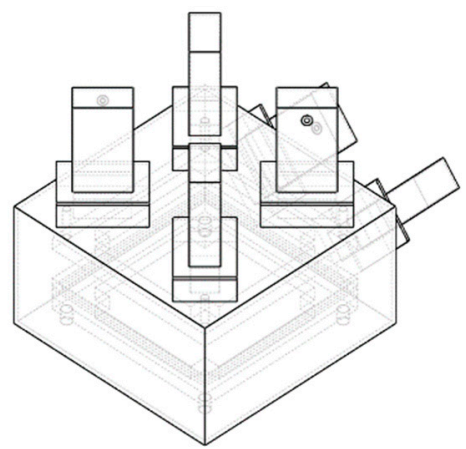

(c) Pattern C

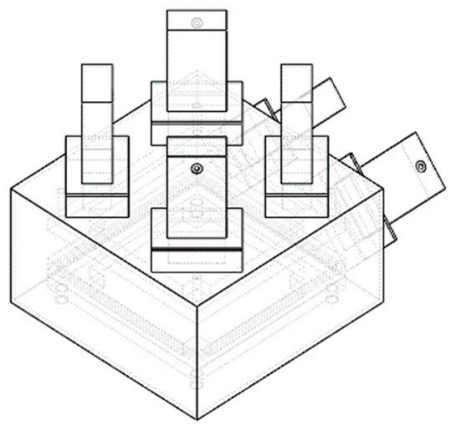

(b) Pattern B

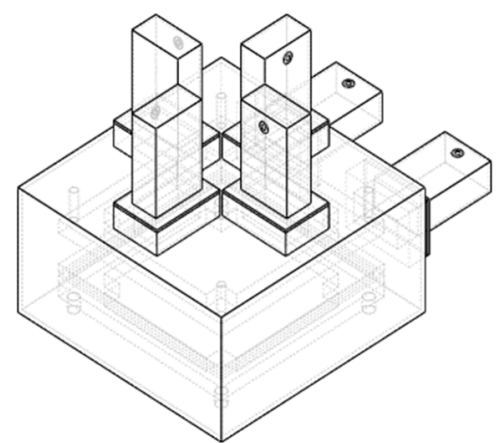

(d) Pattern D

Figure 2. A $6 \mathrm{~kW}$ model microwave chamber with four different waveguide patterns.
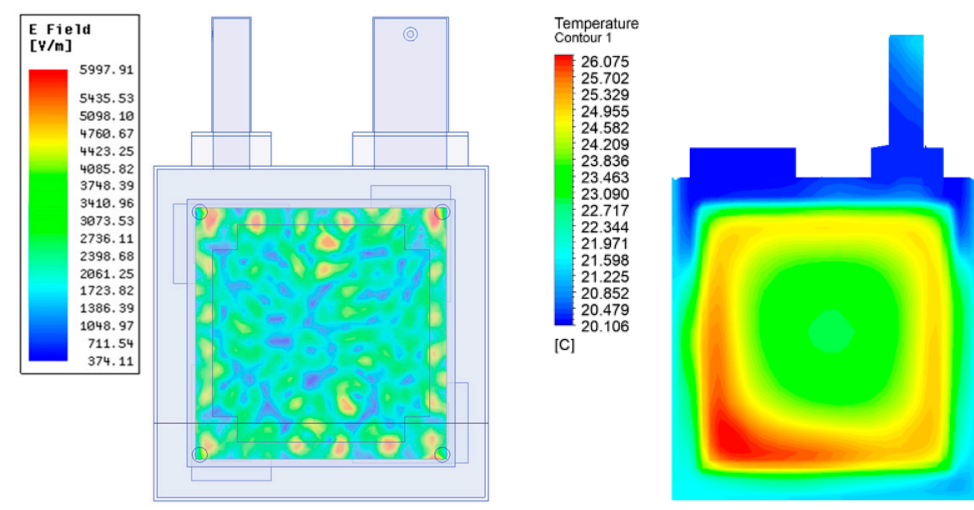

(a) Pattern A
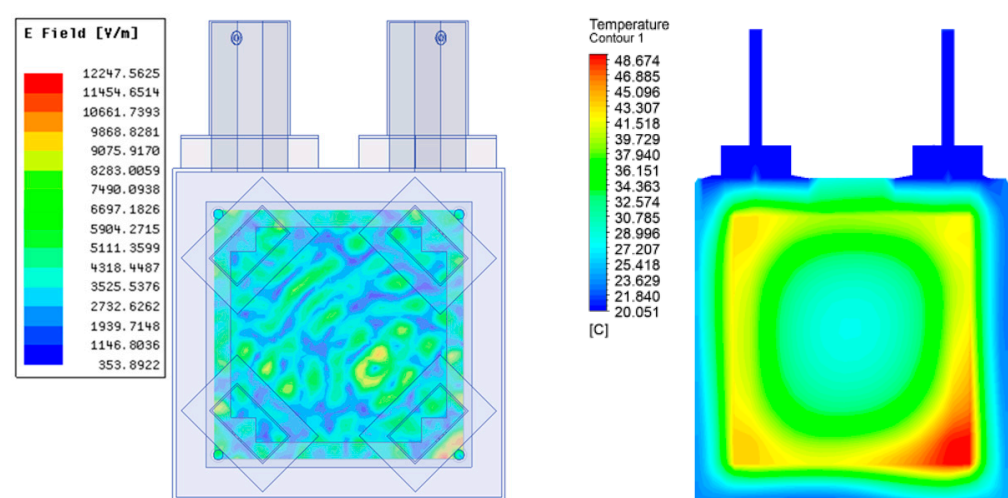

(b) Pattern B

Figure 3. Cont. 

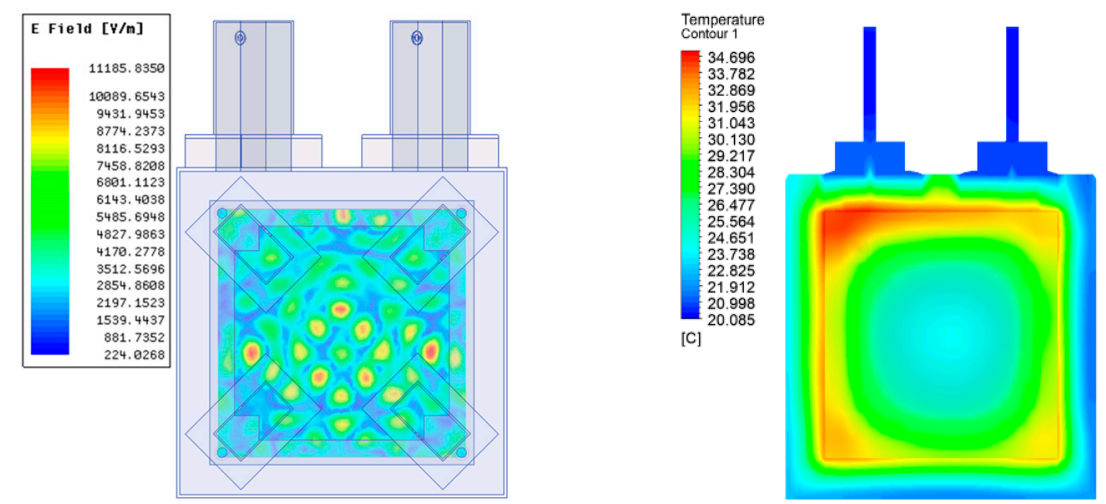

(c) Pattern C
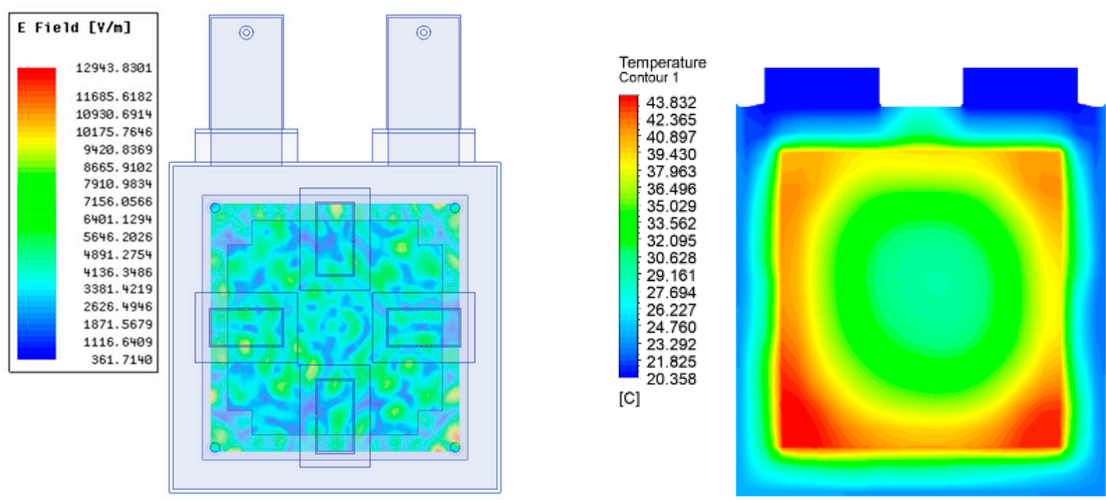

(d) Pattern D

Figure 3. Electric field (left) and temperature distribution (right) results on the glass surface in accordance with the four waveguide patterns shown in Figure 2.

Based on the simulation result by pattern, pattern A was applied in our experiments. However, preventing glass damage caused by temperature concentration and temperature deviation is difficult when applying the waveguide pattern. A susceptor was therefore employed to block microwave absorption and increase thermal diffusion. This is positioned to raise the stable temperature at which the glass is not damaged. Simulation of the electric field and temperature distribution was then conducted. Silicon carbide $(\mathrm{SiC})$ and graphite $(\mathrm{C})$ plates are commonly used susceptor materials in microwave systems [22], due to their dielectric properties and thermal conductivity. Both materials can be heated by absorbing microwaves, and can cause thermal diffusion through high thermal conductivity, thus reducing glass breakage. However, silicon carbide exhibits high covalent bonding and is difficult to process to a hardness higher than that of alumina. Moreover, graphite presents the problem of oxidation at temperatures greater than $700{ }^{\circ} \mathrm{C}$ [23]. In the case of graphite plates, oxidation can be prevented in a reducing or vacuum atmosphere, and so a graphite plate is adopted in the current study.

Figure 4 shows the structure of the glass-heating setup with a graphite susceptor. The simulation results confirm that the electric field distribution in the chamber was altered by the addition of the susceptor. Based on the electric field distribution results, the temperature distribution on the glass was analyzed, and the temperature distribution was higher at points where the electric field distribution was concentrated, as shown in the electric field analysis results. And we confirmed the dissipated power in the susceptor came out to be about $403 \mathrm{~W}$ using field calculator. For the temperature distribution of the glass, it was confirmed that a maximum temperature deviation of approximately $17^{\circ} \mathrm{C}$ is displayed in the glass-heating structures that contained a susceptor. It was confirmed that by absorbing the electric field concentrations using the dielectric properties and thermal conductivity of the graphite, the temperature is diffused across the whole plate with high thermal conductivity. 
Based on this analysis result, it was judged that glass-heating could be performed up to the transition temperature, where glass sealing can be performed using microwaves. Figure 5 shows the electric field, volume loss density and temperature distribution results for the setup with a graphite susceptor.

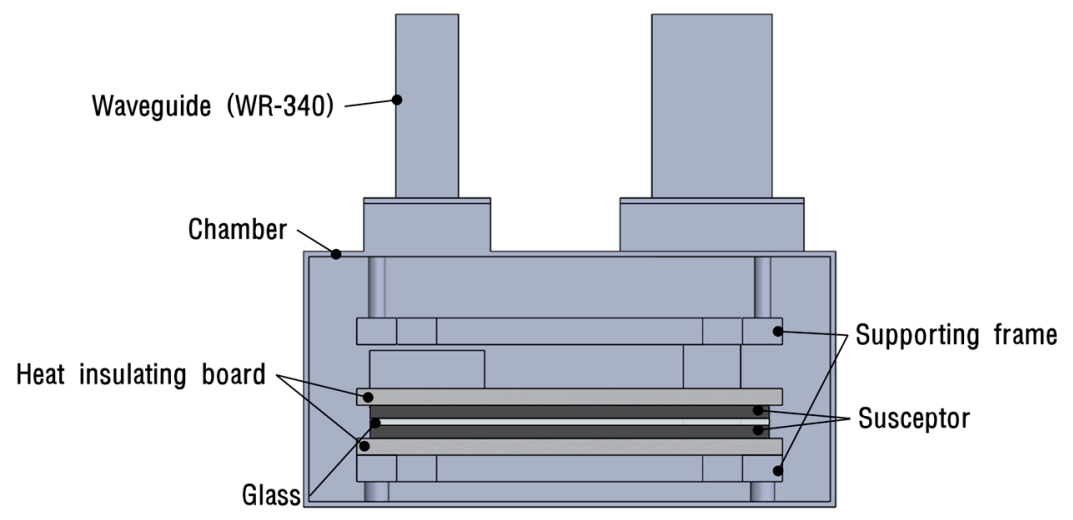

Figure 4. Glass-heating system setup with a graphite susceptor.

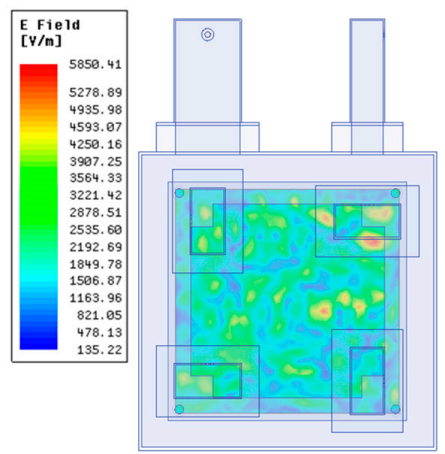

(a)

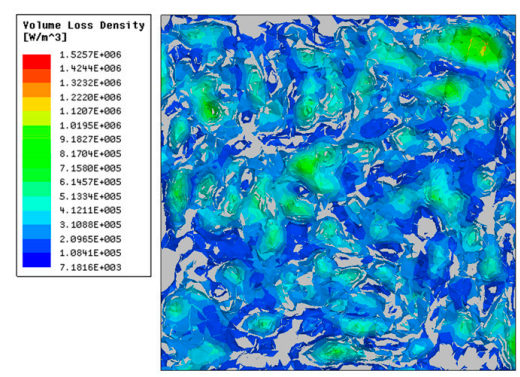

(b)

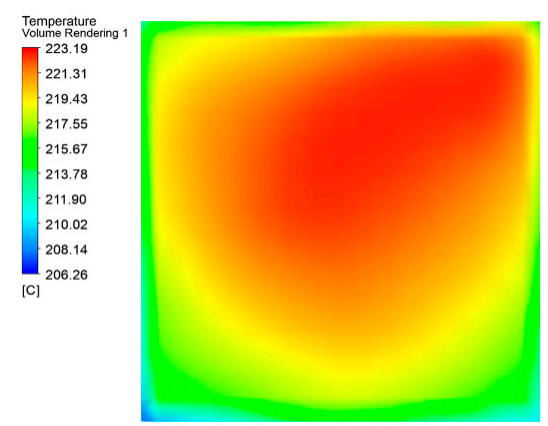

(c)

Figure 5. Electric field (a), volume loss density (b) and temperature distribution (c) results on the glass surface in accordance with the glass-heating system shown in Figure 4, with a graphite susceptor. 


\section{Flat-Glass Heating and Edge-Sealing Experiments}

\subsection{Basic Flat-Glass Heating Experiments}

A microwave chamber was constructed for the edge-sealing of glass. The design and construction were completed based on the analysis results for electromagnetic field distribution shown in the previous section. Figure 6 shows the layout of the microwave chamber and an image of the assembled apparatus.
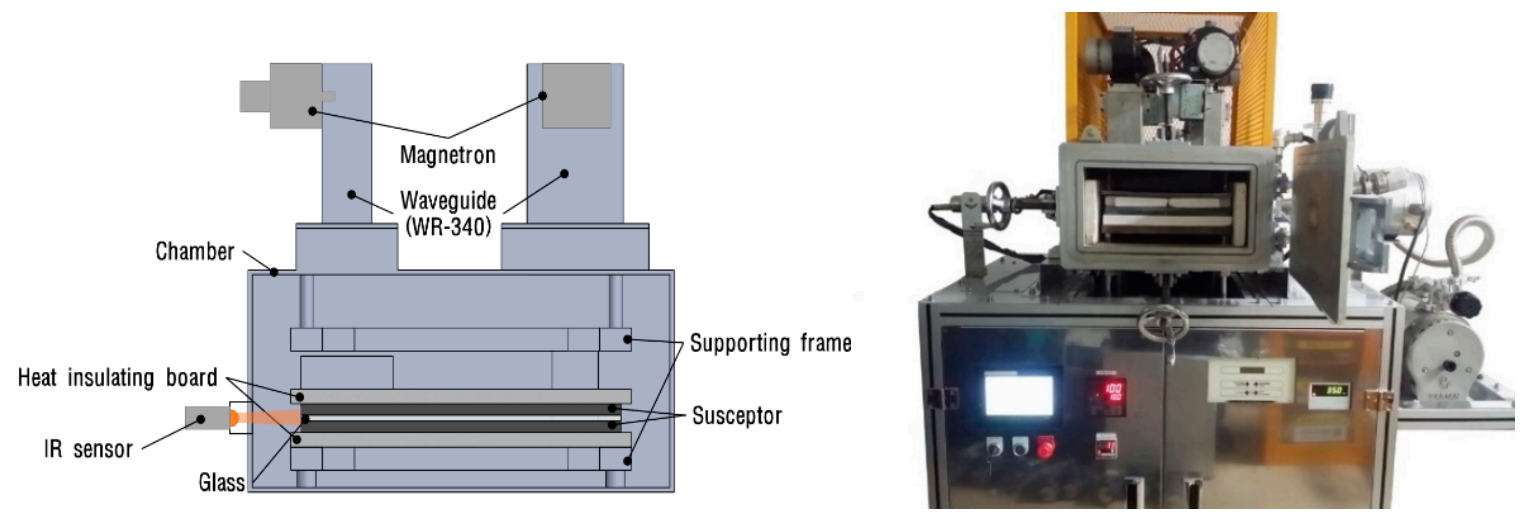

Figure 6. Schematic illustration (left) and image of the experimental microwave glass-heating chamber (right).

Prior to glass bonding, a basic experiment was conducted to raise the temperature of the glass to the transition temperature. First, a heating experiment was conducted on glass with a thickness of $5 \mathrm{~mm}$. The conditions for the basic experiment were conducted based on the target temperature for heating and the heating rate. After the experiment, the experimental glass is removed from the chamber, visual observation determines whether the glass is broken, and the temperature distribution is measured using a thermal imaging camera (Fluke Ti 125).

The conditions of the first experiment were set to a target temperature of $20{ }^{\circ} \mathrm{C}$. The experimental results shown in Figure 7 confirm a concentration of heat due to the concentration of microwaves in a specific position in the chamber, at temperatures up to $280^{\circ} \mathrm{C}$. It was confirmed that the glass was broken during heating and glass cracked all along the sheet.
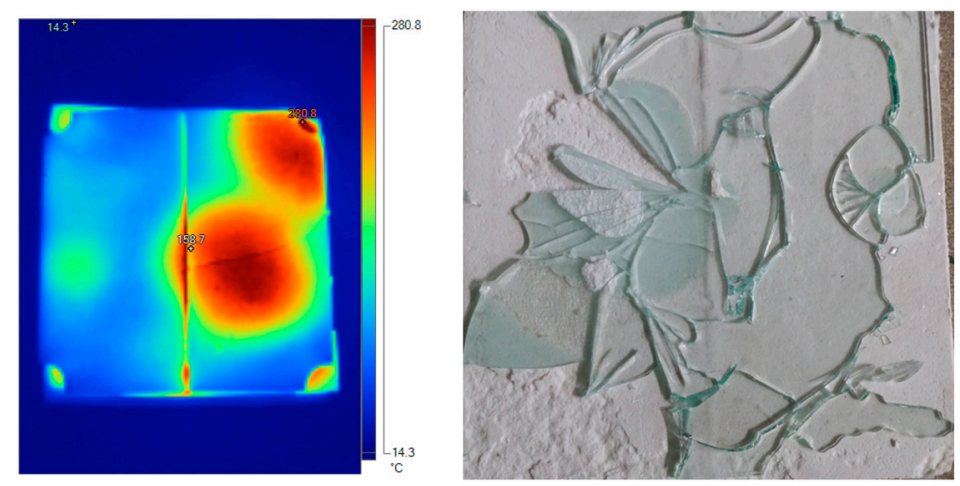

Figure 7. Experimental results obtained at a temperature of $200{ }^{\circ} \mathrm{C}$ and heating rate $20{ }^{\circ} \mathrm{C} / \mathrm{min}$. Temperature distribution (left) and cracks on the glass (right).

The second set of experimental conditions were a target temperature of $100{ }^{\circ} \mathrm{C}$ and a heating rate of $8^{\circ} \mathrm{C} / \mathrm{min}$, based on the temperature rise curve of the ambient temperature for glass edge-sealing using a conventional hydrogen mixed gas [7]. Figure 8 shows the results of the experiment, with a maximum temperature of $78.2^{\circ} \mathrm{C}$ and a minimum temperature of $37.6^{\circ} \mathrm{C}$. The temperature deviation is significant, but glass fracture did not occur. The temperature distribution appears to be similar to the 
result obtained using electric field distribution analysis (Figure 3), and the high temperature is mainly concentrated at the side and edge positions on the glass.
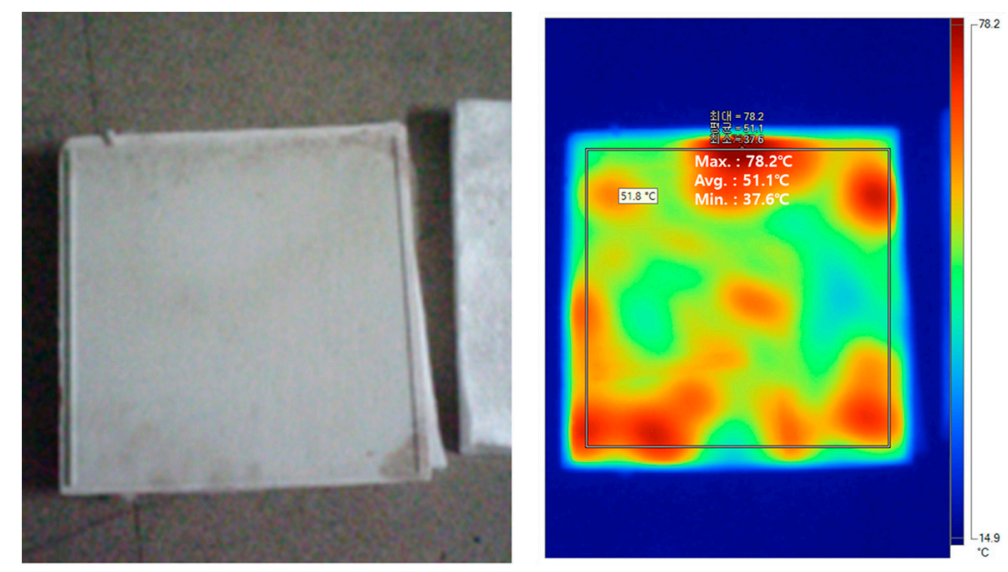

Figure 8. Experimental for a glass-heating temperature of $100{ }^{\circ} \mathrm{C}$ and a heating rate of $8{ }^{\circ} \mathrm{C} / \mathrm{min}$. An image of the glass (left) and the corresponding temperature distribution (right).

In a third set of experimental conditions, the target temperature was set to $200^{\circ} \mathrm{C}$ and the heating rate was maintained at $8^{\circ} \mathrm{C} / \mathrm{min}$. Figure 9 shows the results of this experiment. The glass exhibits a large temperature difference, with a maximum of $232^{\circ} \mathrm{C}$ and minimum of $117^{\circ} \mathrm{C}$, and breakage occurred. As a result, it was judged that a further temperature increase would only result in glass fracture, and further experiments were conducted using a graphite susceptor.
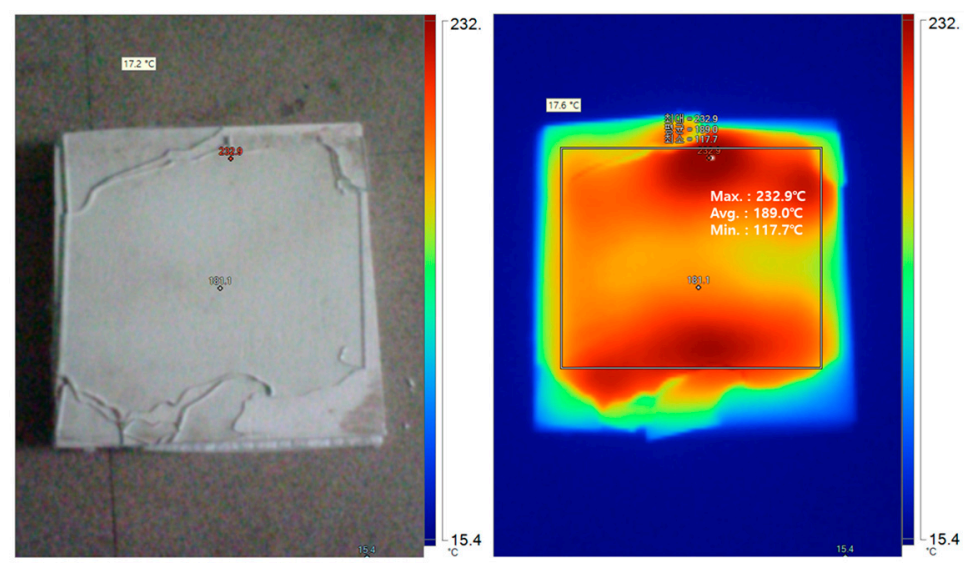

Figure 9. Experimental results obtained at a temperature of $200{ }^{\circ} \mathrm{C}$ and a heating rate of $8{ }^{\circ} \mathrm{C} / \mathrm{min}$. An image of the glass (left) and the temperature distribution (right).

In a fourth experiment, a graphite susceptor was positioned at the lower and upper parts of the glass, and then the same experiment conditions were used as in the third experiment.

Figure 10 shows the results of this experiment, and the temperature was uniform after reaching a temperature of $161{ }^{\circ} \mathrm{C}$. The glass exhibits a small temperature difference with a maximum $161.8^{\circ} \mathrm{C}$ and minimum of $132.9^{\circ} \mathrm{C}$, and breakage did not occur. It was judged that it is possible to reach the transition temperature of glass without breakage. 


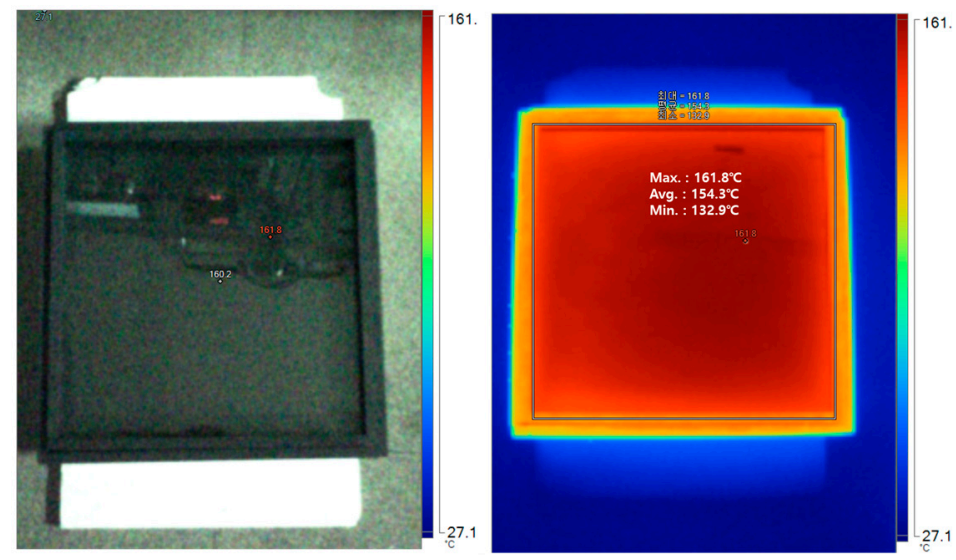

Figure 10. Experimental results for the heating system with a susceptor at a target temperature of $200{ }^{\circ} \mathrm{C}$ and a heating rate of $8{ }^{\circ} \mathrm{C} / \mathrm{min}$. An image of the glass (left) and the temperature distribution (right).

In a fifth experiment, heating was conducted using the susceptor arrangement, a target temperature of $500{ }^{\circ} \mathrm{C}$, and a heating rate of $8{ }^{\circ} \mathrm{C} / \mathrm{min}$. The state of the glass is confirmed after all cooling has occurred because glass may be fractured due to sudden temperature changes upon removal from the chamber into a room temperature environment. The increases in temperature were confirmed using an infrared thermometer, and the experimental results are shown in Figure 11. It was confirmed that some deformation occurred due to temperature concentration at the corners of the glass, as the rest of the glass was not damaged. Although it appears that in this experiment, the temperature had risen to the transition temperature at which glass can be deformed at the corner, it is considered that sealing the edges of the glass using the susceptor is feasible as the glass was not fractured.

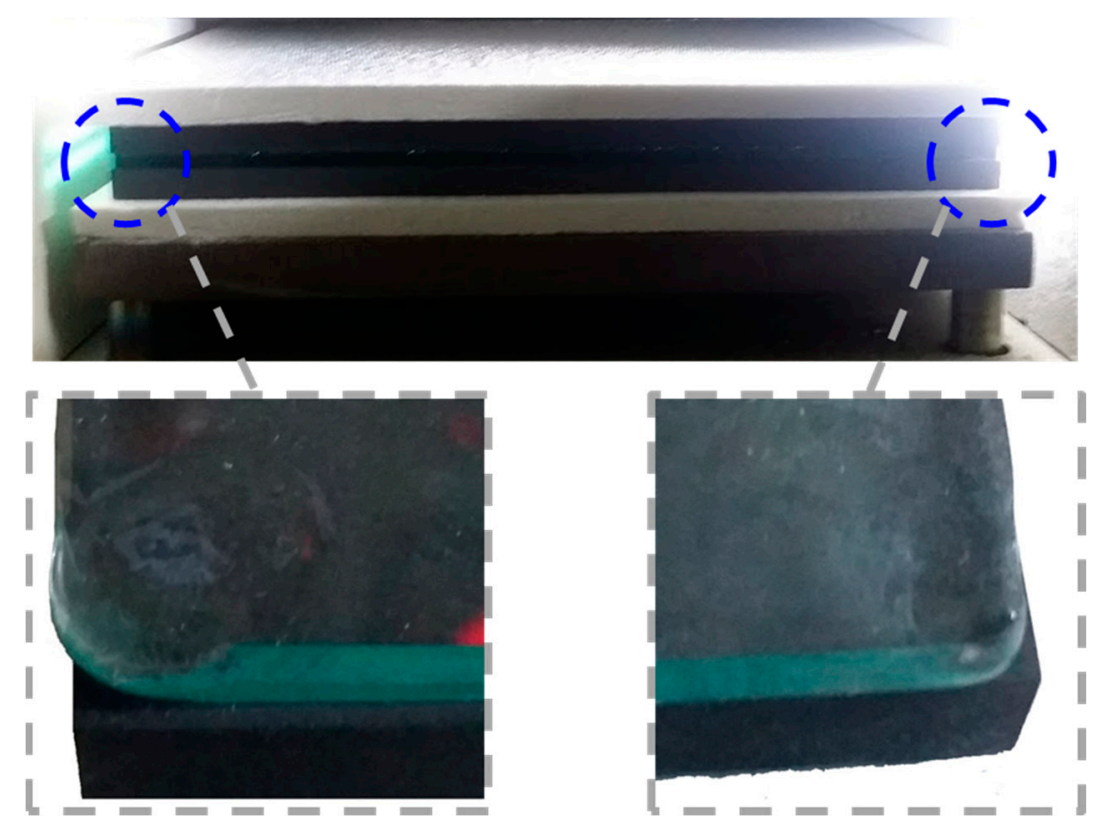

Figure 11. Experimental results obtained with a susceptor, a target temperature of $500{ }^{\circ} \mathrm{C}$, and a heating rate of $8^{\circ} \mathrm{C} / \mathrm{min}$. The experimental system (left), deformation at the glass corners (middle and right).

\subsection{Glass Edge-Sealing Experiment}

A thin sheet of glass with a thickness of $0.5 \mathrm{~mm}$ is placed between two soda-lime glass panes to maintain a constant distance between the glass panes, each with a thickness of $5 \mathrm{~mm}$. Figure 12 shows a schematic illustration of the system for glass edge-sealing. Microwave irradiation and glass 
edge-sealing by pressing the glass edges of was conducted at the glass transition temperature in this experiment.

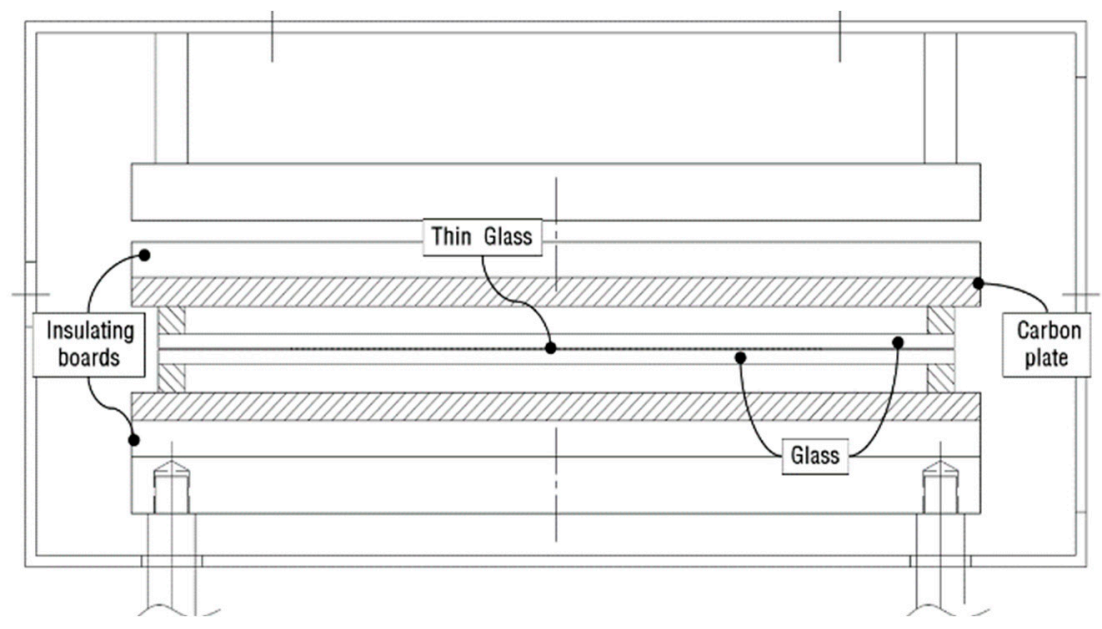

Figure 12. Schematic illustration of the experimental setup used for glass edge-sealing.

The cross-sectional properties were confirmed by cutting with a water jet, in order to confirm whether the glass was sealed. As shown in Figure 13, it was confirmed that all four edge of the glass were completely pressed and sealed. As shown in the cross-sectional view, the press part of the edge of the glass was pressed securely without cracking or breakage, and the inner side between the glass pane was kept as thin as the thin glass of $0.5 \mathrm{~mm}$ thickness.

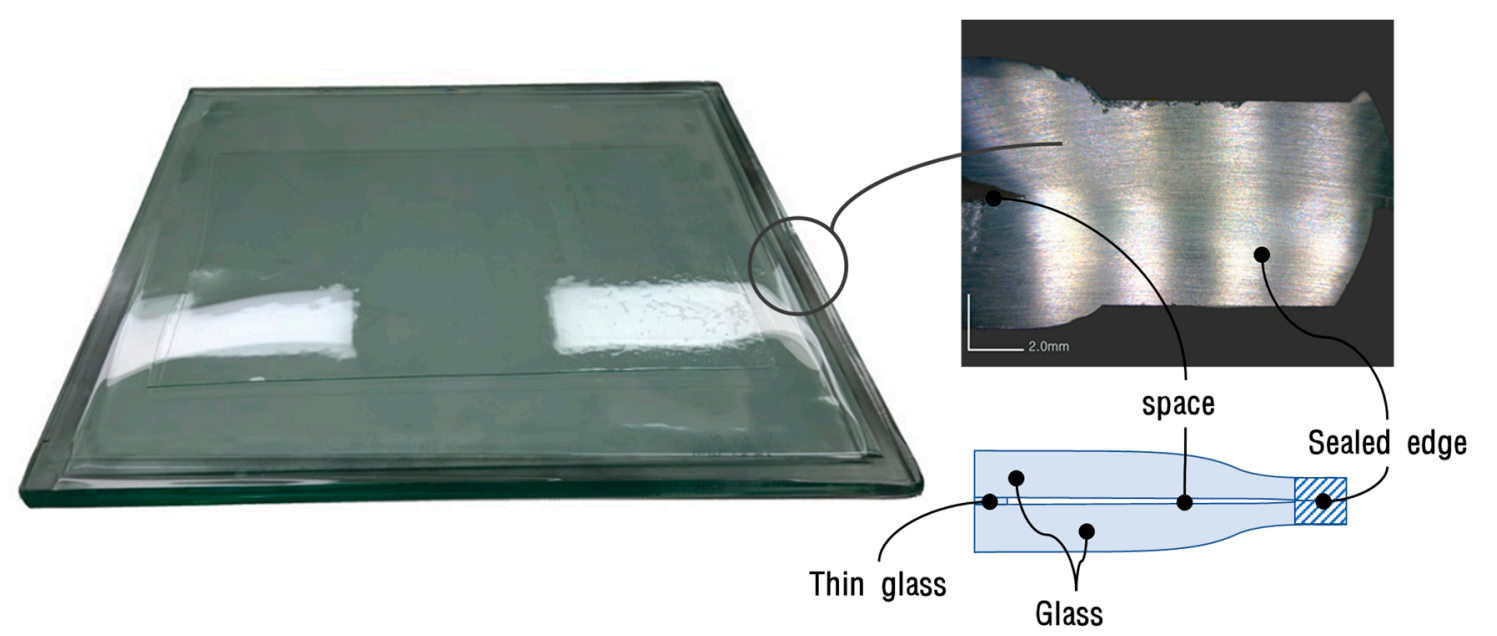

Figure 13. A sealed glass sample. View of the glass pane (left) and a cross-sectional view (right).

\section{Conclusions}

In this paper, a study on heating and edge-sealing flat glass using microwave radiation was undertaken, involving both simulation and experiment.

1. We present a novel method for heating and edge-sealing flat glass using microwaves. Simulation involving multiple sources was performed and the appropriate waveguide patterns were derived.

2. A $6 \mathrm{~kW}$ microwave chamber was then constructed, and heating experiments were performed under various conditions.

3. Glass panes were heated to the glass transition temperature and confirmed that these were sealed by edge pressure, using a system with graphite susceptors. These results indicate 
the potential for this flat-glass heating and edge-sealing method to be applied in vacuum glazing manufacturing processes. Further research is needed on the edge-sealing process in a vacuum environment.

Author Contributions: J.K.K., Y.S.K. and E.S.J. conceived and designed the experiments; J.K.K. performed the simulations and experiments; J.K.K. and Y.S.K. analyzed the data; J.K.K., Y.S.K and E.S.J. contributed reagents/materials/analysis tools; J.K.K., Y.S.K. and E.S.J. wrote the paper.

Funding: This research was supported by the Basic Science Research Program through the National Research Foundation of Korea (NRF), funded by the Ministry of Science, ICT, \& Future Planning (NRF-2017R1A2B4009929).

Conflicts of Interest: The authors declare no conflict of interest.

\section{References}

1. Cuce, E.; Cuce, P.M. Vacuum glazing for highly insulating windows: Recent developments and future prospects. Renew. Sustain. Energy Rev. 2016, 54, 1345-1357. [CrossRef]

2. Asphaug, S.K.; Jelle, B.P.; Gullbrekken, L.; Uvsløkk, S. Accelerated ageing and durability of double-glazed sealed insulating window panes and impact on heating demand in buildings. Energy Build. 2016, 116, 395-402. [CrossRef]

3. Memon, S.; Farukh, F.; Eames, P.; Silberschmidt, V. A new low-temperature hermetic composite edge seal for the fabrication of triple vacuum glazing. Vacuum 2015, 120, 73-82. [CrossRef]

4. Miao, H.; Shan, X.; Zhang, J.; Sun, J.; Wang, H. Effect of sealing temperature on the sealing edge performance of vacuum glazing. Vacuum 2015, 116, 7-12. [CrossRef]

5. Zhang, J.; Liu, S.; Zhang, Y.; Miao, H.; Zhang, S.; Zhang, Q. Formation mechanism of sealing edge pores for vacuum glazing using laser brazing technique. Vacuum 2015, 147, 1-7. [CrossRef]

6. Kim, Y.S.; Jeon, E.S. Using a hydrogen gas torch to seal edges of vacuum glazing panels and related characteristic strength analyses according to sealed edge shapes. Vacuum 2018, 149, 262-269. [CrossRef]

7. Kim, Y.S.; Jeon, E.S. Establishment of regression model for estimating shape parameters for vacuum-sealed glass panel using design of experiments. Vacuum 2015, 121, 113-119. [CrossRef]

8. Zhu, H.; He, J.; Hong, T.; Yang, Q.; Wu, Y.; Yang, Y.; Huang, K. A rotary radiation structure for microwave heating uniformity improvement. Appl. Therm. Eng. 2018, 141, 648-658. [CrossRef]

9. Heddleson, R.A.; Doores, S. Factors affecting microwave heating of foods and microwave induced destruction of foodborne pathogens-A review. Food Prot. 1996, 57, 1025-1037. [CrossRef]

10. Li, Z.Y.; Wang, R.F.; Kudra, T. Uniformity issue in microwave drying. Dry. Technol. 2011, 29, $652-660$. [CrossRef]

11. Plaza-Gonzalez, P.; Monzo-Cabrera, J.; Catala-Civera, J.M.; Sanchez-Hernandez, D. Effect of Mode-Stirrer Configurations on Dielectric Heating Performance in Multimode Microwave Applicators. IEEE TMTT 2005, 53, 1699-1706. [CrossRef]

12. Bows, J.R. Variable frequency microwave heating of food. Microw. Power Electromagn. Energy 1999, 34, 227-238. [CrossRef] [PubMed]

13. Watanabe, S.; Karakawa, M.; Hashimoto, O. Computer simulation of temperature distribution of frozen material heated in a microwave oven. IEEE Trans. Microw. Theory Technol. 2010, 58, 1196-1204. [CrossRef]

14. Javier, G.S.; de los Reyes, R.; Jara, A.; de los Reyes, E.R. Microwave energy transduction using planar technology. Electron. Lett. 2015, 51, 499-501.

15. Sun, T. Key models of heat and mass transfer of asphalt mixtures based on microwave heating. Dry. Technol. 2014, 32, 1568-1574. [CrossRef]

16. Dominguez-Tortajada, E.; Monzo-Cabrera, J.; Diaz-Morcillo, A. Uniform electric field distribution in microwave heating applicators by means of genetic algorithms optimization of dielectric multilayer structures. IEEE Trans. Dielectr. Electr. Insul. 2007, 55, 85-91. [CrossRef]

17. Hassan, O.A.; Kandil, A.H.; el Bialy, A.M.; Hassaballa, I.A. Improving heating uniformity of pathological tissue specimens inside a domestic microwave oven. J. Microw. Power Electron. Energy 2013, 47, 87-101. [CrossRef]

18. Yoshikawa, N.; Wang, H.; Mashiko, K.; Taniguchi, S. Microwave heating of soda-lime glass by addition of iron powder. J. Master. Res. 2007, 23, 1564-1569. [CrossRef] 
19. Wu, H.; Grabarnik, S.; Emadi, A.; de Graaf, G.; Wolffenbuttel, R.F. Characterization of thermal cross-talk in a MEMS-based thermopile detector array. J. Micromech. Microeng. 2009, 19, 1-7. [CrossRef]

20. Fenske, K.; Misra, D. Dielectric Materials at Microwave Frequencies. Appl. Microw. Wirel. 2000, 12, 92-100.

21. Hill, J.M.; Marchant, T.R. Modelling microwave heating. Appl. Math. Model. 1996, 20, 3-15. [CrossRef]

22. Aravindan, S.; Krishnamurthy, R. Joining of ceramic composites by microwave heating. Mater. Lett. 1999, 38, 245-249. [CrossRef]

23. Park, H.-K.; Park, S.-H.; Park, I.-S.; Yang, D.-H.; Cha, S.-H.; Ha, B.-C.; Lee, J.-C. Analysis of Grinding Characteristics of Ceramic (SiC) Materials. J. Korean Soc. Manuf. Process Eng. 2018, 17, 16-22. [CrossRef]

(C) 2019 by the authors. Licensee MDPI, Basel, Switzerland. This article is an open access article distributed under the terms and conditions of the Creative Commons Attribution (CC BY) license (http://creativecommons.org/licenses/by/4.0/). 